\title{
Subtype Specification of GABAergic Amacrine Cells by the Orphan Nuclear Receptor Nr4a2/Nurr1
}

\author{
Haisong Jiang ${ }^{1,2,3}$ and Mengqing Xiang ${ }^{1,2,3}$ \\ ${ }^{1}$ Center for Advanced Biotechnology and Medicine, ${ }^{2}$ Department of Pediatrics, and ${ }^{3}$ Graduate Program in Molecular Genetics and Microbiology, University \\ of Medicine and Dentistry of New Jersey-Robert Wood Johnson Medical School, Piscataway, New Jersey 08854
}

In the mammalian retina, amacrine cells (ACs) contain numerous subtypes with extremely diverse morphologies and physiological functions. To date, how these subtypes arise during retinogenesis remains largely unknown at the molecular level. The orphan nuclear receptor Nr4a2 plays an essential role in specifying ventral midbrain dopaminergic neurons, and its mutations are associated with familial Parkinson's disease. Here we show that $\mathrm{Nr} 4 \mathrm{a} 2$ is also critically involved in the specification of AC subtype identity. During mouse retinogenesis, $\mathrm{Nr} 4 \mathrm{a} 2$ is expressed in a subset of postmitotic GABAergic ACs and their precursors. Its targeted inactivation results in the loss of a subpopulation of GABAergic ACs that include all dopaminergic and p57Kip2 ${ }^{+}$neurons as well as a simultaneous increase of calbindin ${ }^{+}$ACs. Misexpressed Nr4a2 can promote GABAergic AC differentiation and repress calbindin ${ }^{+}$ACs, whereas its dominantnegative form has the ability to suppress the GABAergic AC fate. Moreover, the expression of Nr4a2 is positively regulated by Foxn 4 and negatively controlled by Brn3b, two retinogenic factors previously shown to promote and suppress GABAergic ACs, respectively. These data suggest that $\mathrm{Nr} 4 \mathrm{a} 2$ is both necessary and sufficient to confer $\mathrm{AC}$ precursors with the identity of a GABAergic AC phenotype, and that it may network with multiple other retinogenic factors to ensure proper specification and differentiation of AC neurotransmitter subtypes.

\section{Introduction}

The mammalian retina is a laminated sensorineural epithelium composed of six classes of neurons that include the rod, cone, bipolar, horizontal, amacrine (AC), and ganglion cells (RGCs), and one type of glia, the Müller cells. Of the six classes of neurons, ACs are most diversified and play major roles in the processing of visual information. They can be classified into at least 28 subtypes based on their morphologies, sublaminar positions, physiological properties, and functions (MacNeil and Masland, 1998; MacNeil et al., 1999; Masland, 2001b). The great majority of them contain either glycine or GABA inhibitory neurotransmitters, thereby forming two major groups-glycinergic and GABAergic-with each comprising 40\% of the total AC population (Vaney, 1990; Marquardt et al., 2001). AII cells link the rod pathway to the cone circuitry by synapsing on both rod and cone bipolar cells (Kolb and Famiglietti, 1974; Famiglietti and Kolb, 1975; Vaney, 1985; Strettoi et al., 1992). Dopaminergic neurons represent a GABAergic subtype that exerts multiple modulatory effects on the retinal circuitry. These include reducing gap-junction conductance between horizontal cells and altering the center-surround organi-

Received June 26, 2009; accepted July 21, 2009.

This work was supported by National Institutes of Health Grants EY012020 and EY015777 (to M.X.). We thank Dr. Orla Conneely (Baylor College of Medicine) for providing the Nr4a2 knock-out mice, Dr. Alexander Dizhoor (Pennsylvania College of Optometry) for the anti-recoverin antibody, and members of the Xiang laboratory for valuable discussion of the project and thoughtful comments on the manuscript.

Correspondence should be addressed to Dr. Mengqing Xiang, Center for Advanced Biotechnology and Medicine, 679 Hoes Lane, Piscataway, NJ 08854. E-mail: xiang@cabm.rutgers.edu.

DOI:10.1523/JNEUROSCI.3048-09.2009

Copyright $\odot 2009$ Society for Neuroscience 0270-6474/09/2910449-11\$15.00/0 zation of ganglion cells (Jensen and Daw, 1984; Piccolino et al., 1987; Jensen, 1992; Gustincich et al., 1997).

During retinogenesis, all cell types, including ACs, are produced from multipotent progenitors in a developmental process requiring coordinated action of various intrinsic and extrinsic factors (Harris, 1997; Cepko, 1999; Livesey and Cepko, 2001). Several transcription factors act as intrinsic regulators to control the fate commitment and differentiation of ACs. These include Foxn4, which is required by progenitors to establish the competence state for AC generation (Li et al., 2004), and Math3, Neurod1, and Ptfla, which are required for specifying the $\mathrm{AC}$ fate (Morrow et al., 1999; Inoue et al., 2002; Fujitani et al., 2006; Nakhai et al., 2007). The intrinsic mechanism underlying specification of the vast AC subtypes is largely unknown at present. Pax6 and Barhl2 have been implicated as playing a role in specifying glycinergic ACs (Marquardt et al., 2001; Mo et al., 2004), and Bhlhb5 and Isl1 in specifying GABAergic and cholinergic ACs, respectively (Feng et al., 2006; Elshatory et al., 2007).

$\mathrm{Nr} 4 \mathrm{a} 2 / \mathrm{Nurr} 1$ is an orphan nuclear receptor that functions in a ligand-independent manner (Wang et al., 2003). It is expressed predominantly by dopaminergic neurons of the ventral midbrain and has been demonstrated to play an essential role in dopaminergic neuron development (Zetterström et al., 1997; SaucedoCardenas et al., 1998). Nr4a2 inactivation causes a failure in the specification of midbrain dopaminergic neurons whereas its overexpression promotes the differentiation of dopaminergic neurons from stem cells (Zetterström et al., 1997; SaucedoCardenas et al., 1998; Martinat et al., 2006). In the human, mutations in NR4A2 are associated with familial Parkinson's disease (Le et al., 2003), reinforcing its potential in causing and treating 
neurodegenerative disorders. We have previously identified Nr4a2 as a downstream gene repressed by Brn3b during mouse retinogenesis (Qiu et al., 2008), thereby leading to the speculation that Brn3b may inhibit the formation of dopaminergic ACs by negatively regulating Nr4a2 expression. To test this hypothesis and to investigate whether $\mathrm{Nr} 4 \mathrm{a} 2$ plays any role during retinal development, we examined its expression and analyzed its biological function in the retina. Our results demonstrate a crucial role for $\mathrm{Nr} 4 \mathrm{a} 2$ in specifying a subset of GABAergic ACs that include all dopaminergic neurons.

\section{Materials and Methods}

Animals. The Nr4a2 knock-out mice were produced in and obtained from Dr. Orla Conneely's laboratory (Saucedo-Cardenas et al., 1998), and the Foxn4 and Brn3b knock-out mice were generated and maintained in our laboratory (Gan et al., 1996; Li et al., 2004). The stage of mouse embryos was determined by taking the morning when the copulation plug was seen as embryonic day 0.5 (E0.5). All genotypes described were confirmed by PCR.

Virus preparation and infection. To construct the Nr4a2-GFP (green fluorescent protein) plasmid, a full-length human Nr4a2 cDNA was bluntly ligated into the control-GFP viral vector (Mo et al., 2004). To construct the Nr4a2-EnR-GFP plasmid, a DNA fragment containing the Nr4a2 DNA-binding domain (amino acids 94-365) fused in frame with the repressor domain of the Drosophila engrailed protein was ligated into the Control-GFP vector. Virus preparation and infection were performed as described previously (Li et al., 2004; Mo et al., 2004). Retinas were infected in vivo at postnatal day $0(\mathrm{P} 0)$ with desired retroviruses and then harvested and analyzed at P21. Explanted retinas were infected at E14.5 and harvested for analysis after $12 \mathrm{~d}$ in culture.

Immunofluorescence and quantification. The preparation of retinal sections and immunofluorescent labeling of retinal sections and wholemount retinas were performed as described previously (Li et al., 2004; Mo et al., 2004). The following primary antibodies were used: antityrosine hydroxylase (TH) (rabbit polyclonal; Millipore Bioscience Research Reagents); anti-syntaxin (mouse monoclonal; Sigma); anti-GABA (rabbit polyclonal; Sigma); anti-calbindin-D28K (rabbit polyclonal; Swant); anti-Lim1/2 (mouse monoclonal; Developmental Studies Hybridoma Bank, University of Iowa); anti-Brn3a (mouse monoclonal; Millipore); anti-Brn3b (goat polyclonal; Santa Cruz Biotechnology); anti-Pax6 (rabbit polyclonal; Millipore); anti-GFP [rabbit polyclonal (MBL International); goat polyclonal (Abcam)]; anti-recoverin (rabbit polyclonal) (Dizhoor et al., 1991); anti-glycine transporter 1 (GLYT1) (goat polyclonal; Millipore); anti-Chx10 (sheep polyclonal; Exalpha Biologicals); anti-protein kinase C (PKC) (mouse monoclonal; GE Healthcare); anti-Nr4a2 (rabbit polyclonal and goat polyclonal; Santa Cruz Biotechnology); anti-p57Kip2 (rabbit polyclonal; Santa Cruz Biotechnology); anti-aromatic L-amino acid-decarboxylase (AADC) (rabbit polyclonal; Abcam); anti-Bhlhb5 (goat polyclonal; Santa Cruz Biotechnology); anti-calretinin (mouse monoclonal; Millipore); anti-AP- $2 \alpha$ (mouse monoclonal; Santa Cruz Biotechnology); anti-Prox1 (rabbit polyclonal; Covance); anti-Isl1 (mouse monoclonal; Developmental Studies Hybridoma Bank); anti-glutamine synthase (mouse monoclonal; Millipore); anti-GAD67 (mouse monoclonal; Millipore); antiGAD65 (mouse monoclonal; BD), and anti-NF150 (rabbit polyclonal; Millipore). Alexa Fluor 488/594-conjugated donkey IgGs (anti-different species) were used as secondary antibodies (Invitrogen) and $4^{\prime}, 6-$ diamidino-2-phenylindole (DAPI) (Vector Laboratories) or TOPRO3 (Invitrogen) for nuclear counterstaining.

To quantify immunoreactive cells in P0 Nr4a2 wild-type and mutant retinal explants, stained slides were masked and the number of markerpositive cells was scored on retinal sections of the intermediate region in an optical field using a reticule mounted on the microscope. Twelve fields were counted for each retina, and four independent retinas were scored for each type. All marker-positive cells were counted at a magnification of 1000 except for p57Kip2 ${ }^{+}$ACs and calbindin ${ }^{+}$horizontal cells, which were counted at a magnification of 400 , and $\mathrm{TH}^{+} \mathrm{ACs}$, which were counted at a magnification of 100 , due to the paucity of these positive cells. To quantify $\mathrm{GFP}^{+}$cells and $\mathrm{GFP}^{+}$cells colocalized with cell typespecific markers on sections of retinas infected with control-GFP, Nr4a2GFP, or Nr4a2-EnR-GFP viruses, $>400 \mathrm{GFP}^{+}$cells were usually scored for each retina, and at least three retinas were counted for each type. All data were tested for significance using two sample Student's $t$ test with unequal variances.

In situ hybridization, BrdU labeling, and TUNEL assay. RNA in situ hybridization was performed as described using digoxigenin-labeled antisense riboprobes (Liu et al., 2001; Mo et al., 2004). The murine Nr4a2 probe contains $\sim 600 \mathrm{bp}$ of the open reading frame (1436-2032 bp). BrdU labeling of dividing retinal progenitor cells was performed as previously described (Xiang, 1998).

TUNEL assay was performed using the In Situ Cell Death Detection Kit, TMR Red (Roche Diagnostics) following the manufacturer's protocol except that all sections were counterstained with $0.02 \mu \mathrm{g} / \mathrm{ml}$ DAPI. Three to four independent retinas were collected and analyzed for each type at each stage. For each retina, fluorescence-positive cells were counted from 3-5 sections under the microscope, and images of entire sections were captured with a microscope-mounted digital camera. All data were tested for significance using two sample Student's $t$ test with unequal variances.

Retinal explant culture. Retinal explants were cultured as previously described with modification (Morrow et al., 1999; Dyer and Cepko, 2000). P0 control and mutant retinas were dissected free from the surrounding tissue in prewarmed $\left(37^{\circ} \mathrm{C}\right)$ explant culture medium $[42.5 \%$ DMEM (Invitrogen), 42.5\% F12 Nutrient Mix (Invitrogen), 15\% fetal calf serum, penicillin/streptomycin/L-glutamine (Invitrogen), and $5 \mu \mathrm{M}$ forskolin (Sigma)]. Immediately following dissection, retinas were placed on Millicell filters ( $0.4 \mu \mathrm{m}$ pore size; Millipore) in explant culture medium at $37^{\circ} \mathrm{C}$ and $5 \% \mathrm{CO}_{2}$. The medium was replaced every other day.

\section{Results}

\section{Alteration of Nr4a2 expression in Foxn 4 and Brn3b mutant retinas}

We have reported previously that targeted inactivation of $\mathrm{Brn} 3 \mathrm{~b}$ in mice leads to increased dopaminergic ACs as well as upregulation of $N r 4 a 2$ transcription in embryonic retinas (Qiu et al., 2008). In this study, we further examined Nr4a2 protein expression in Brn3b-null mutant retinas by immunofluorescence with an anti-Nr4a2 antibody. Compared with control retinas, there was a $50-80 \%$ increase in the number of Nr4a2-immunoreactive cells in E18.5 and P3 Brn3b ${ }^{-1-}$ retinas (Fig. $1 A-D, M$ ). The correlative relationship between $\mathrm{Nr} 4 \mathrm{a} 2$, a midbrain dopaminergic neuron specifier factor (Zetterström et al., 1997; SaucedoCardenas et al., 1998), and dopaminergic ACs in Brn3b mutant retinas thus suggests a possibility that $\mathrm{Nr} 4 \mathrm{a} 2$ may play an important role in the differentiation of ACs, in particular, dopaminergic ACs. If so, we would expect to observe a downregulation of Nr4a2 expression in Foxn4 mutant retinas since Foxn4 is critically involved in competence acquisition and fate commitment of ACs ( $\mathrm{Li}$ et al., 2004). Indeed, we found that Nr4a2 expression nearly disappeared in E18.5 Foxn $4^{\text {lacZ/lac } Z}$ retinas (Fig. $1 I, J$ ), consistent with the idea that $\mathrm{Nr} 4 \mathrm{a} 2$ may act downstream of Foxn4 to play a role in AC differentiation. Similarly, we observed a significant increase and a dramatic decrease of Bhlhb5-immunoreactive cells in $\mathrm{Brn}_{3} \mathrm{~b}^{-/-}$and Foxn $4^{\text {lacZ/lacZ }}$ retinas, respectively (Fig. $1 \mathrm{E}-\mathrm{H}, \mathrm{K}-\mathrm{M}$ ), in agreement with the previous demonstration of a crucial role for Bhlhb5 in development of a subset of GABAergic ACs (Feng et al., 2006).

\section{Expression of $\mathrm{Nr} 4 \mathrm{a} 2$ in a subset of GABAergic amacrine cells during retinal development}

As a first step to determine whether $\mathrm{Nr} 4 \mathrm{a} 2$ has a role in $\mathrm{AC}$ development, we performed RNA in situ hybridization and immunostaining analyses to investigate its spatiotemporal expres- 


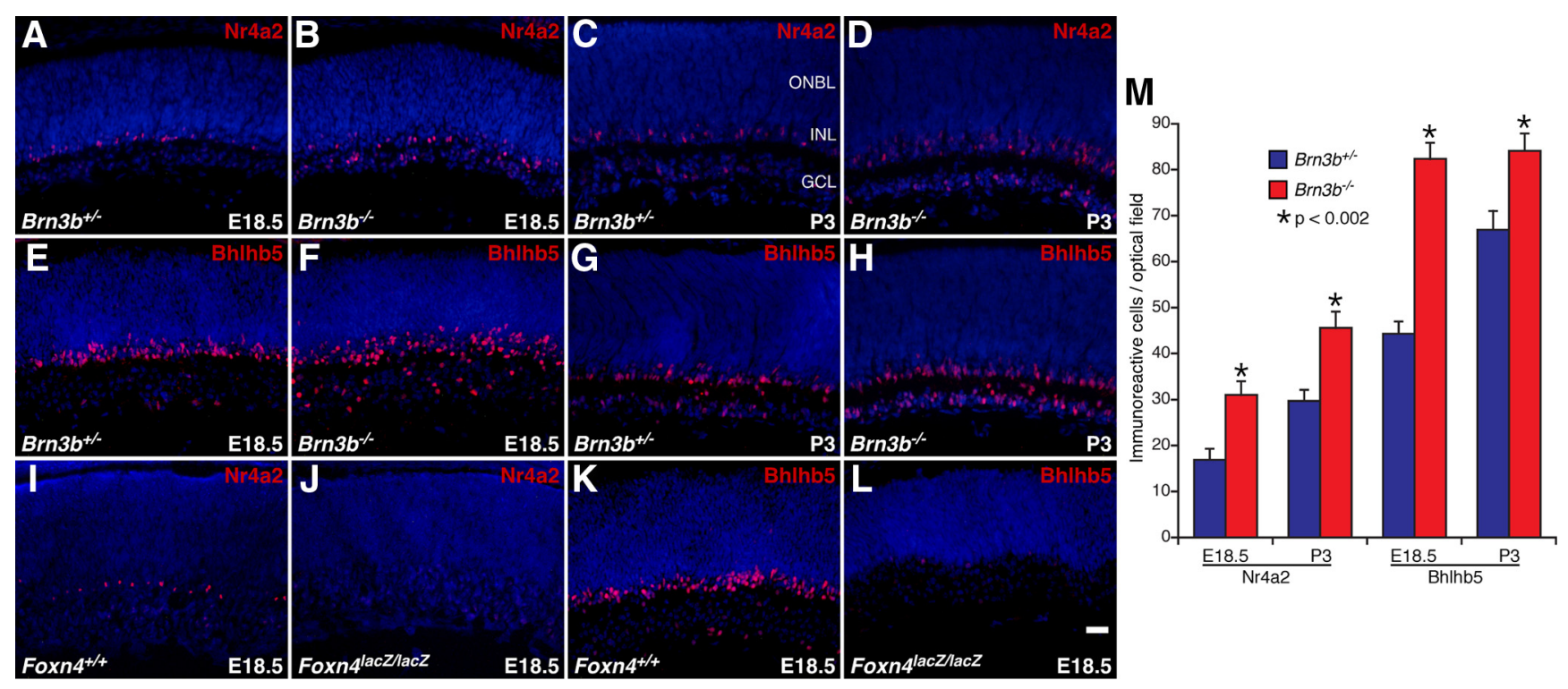

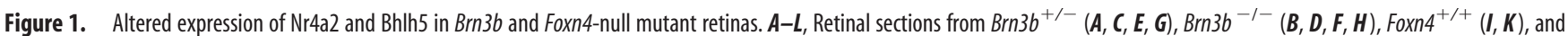
Foxnt $4^{\text {lacZllacz }}(\boldsymbol{J}, \boldsymbol{L})$ mice at the indicated stages were immunostained with antibodies against $\operatorname{Nr} 4 a 2(\boldsymbol{A}-\boldsymbol{D}, \boldsymbol{I}, \boldsymbol{J})$ or Bhlhb5 $(\boldsymbol{E}-\boldsymbol{H}, \boldsymbol{K}, \boldsymbol{L})$, and weakly counterstained with DAPI. There is a significant increase of Nr4a2- and Bhlhb5-immunoreactive cells but a dramatic decrease of these cells in Brn3b $b^{-/-}$and Foxn4 ${ }^{\text {lacZllacz }}$ retinas, respectively. $M$, Quantitation of Nr4a2- and Bhlhb5-

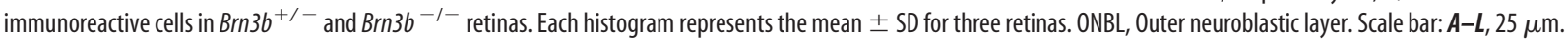
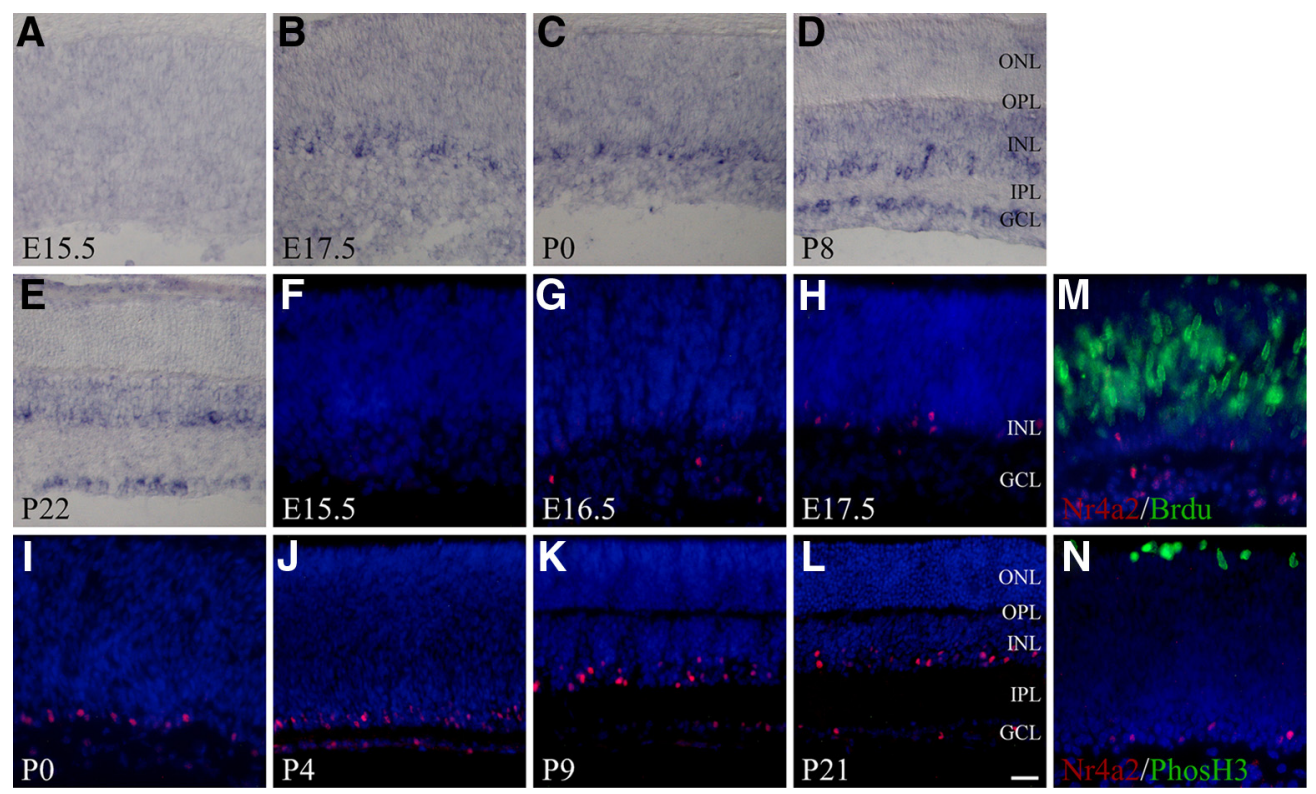

Figure 2. Expression pattern of Nr4a2 during mouse retinogenesis. $\boldsymbol{A}-\boldsymbol{L}$, Retinal sections from the indicated developmental stages were in situ hybridized with a Nr4a2 probe (A-E) or immunostained with an anti-Nr4a2 antibody (red) $(\boldsymbol{F}-\boldsymbol{L})$. Nr4a2 in situ signal is seen in one row of cells at E17.5, then gradually expands to two rows of cells within the INL and the GCL in late postnatal retinas $(\boldsymbol{A}-\boldsymbol{E})$. Similarly, Nr4a2-immunoreactive cells are undetectable at E15.5 but gradually increase from E16.5 to postnatal retinas, where they are maintained within the inner edge of the INL as well as in the GCL $(\boldsymbol{F}-\boldsymbol{L}) . \boldsymbol{M}, \boldsymbol{N}$, Retinal sections from E18.5 embryos pulse labeled with BrdU were double immunostained with antibodies against Nr4a2 and BrdU $(\boldsymbol{M})$, or E18.5 retinal sections were double immunostained with antibodies against Nr4a2 and phosphorylated histone 3 (PhosH3) (N). There is no colocalization between Nr4a2 and BrdU or PhosH3. IPL, Inner plexiform layer; OPL, outer plexiform layer. Scale bar: $A-E, J-L, 25 \mu \mathrm{m} ; F-I, M, N, 16.7 \mu \mathrm{m}$.

sion pattern in the developing mouse retina. Nr4a2 in situ signal was not observed until E16.5-E17.5, when one row of cells was seen to express it in the inner retina (Fig. $2 A, B$ ). It then gradually expanded over time into two rows of cells located within the inner nuclear layer (INL) and ganglion cell layer (GCL) (Fig. $2 B-D$ ). In late postnatal and adult stages (Fig. $2 E$ ), the expressing cells were maintained in the inner half of the INL, where ACs reside, as well as in the GCL, where both ganglion cells and displaced ACs are located. Similarly, Nr4a2-immunoreactive cells were undetect- able at E15.5 in the retina but gradually increased from E16.5 to P0 (Fig. $2 \mathrm{~F}-I$ ). In more postnatal retinas, Nr4a2 was clearly expressed in a subset of neurons located within the inner edge of the INL as well as in the GCL (Fig. $2 J-L$ ), suggesting expression in a subpopulation of ACs and displaced ACs and/or ganglion cells. All Nr4a2-expressing cells are postmitotic, as none of them could be labeled by short pulses of BrdU, an S-phase maker, or by an antibody against phosphorylated histone $\mathrm{H} 3$, an $\mathrm{M}$-phase marker (Fig. $2 M, N)$. 

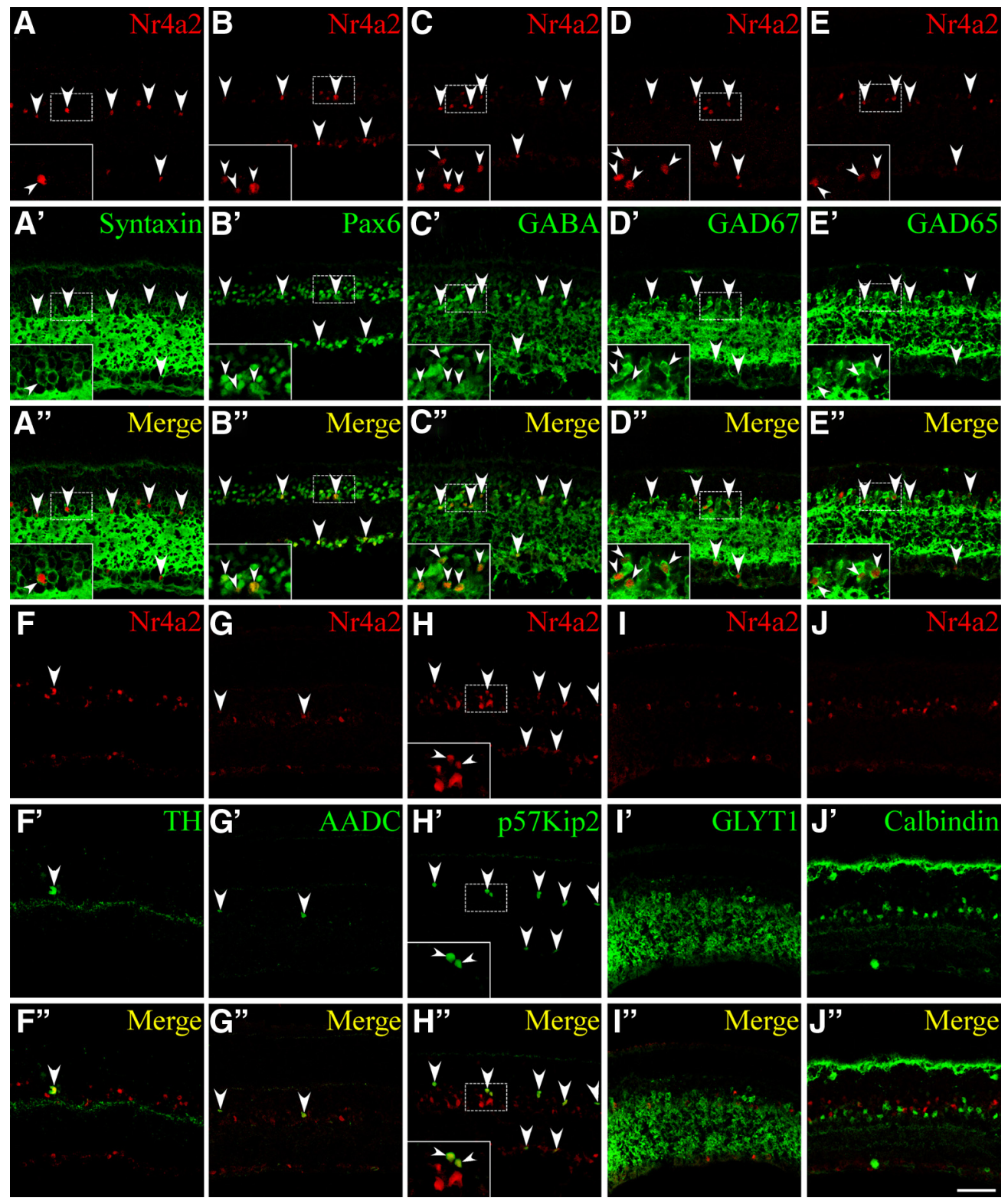

Figure 3. Expression of $\mathrm{Nr} 4 \mathrm{a} 2$ in a subset of GABAergic ACs. $A-\boldsymbol{J}^{\prime \prime}$, Sections from P21 mouse retinas were double immunolabeled with an anti-Nr4a2 antibody and those against the indicated cell type-specific markers. $\boldsymbol{A}-\boldsymbol{A}^{\prime \prime}, \boldsymbol{B}-\boldsymbol{B}^{\prime \prime}$, All Nr4a2 ${ }^{+}$cells are syntaxin ${ }^{+}$and Pax6 ${ }^{+}$ACs. $\mathbf{C}-\boldsymbol{C}^{\prime \prime}, \boldsymbol{D}-\boldsymbol{D}^{\prime \prime}, \boldsymbol{E}-\boldsymbol{E}^{\prime \prime}, \mathrm{Nr} 4 \mathrm{a} 2$ is expressed in a subpopulation of GABA ${ }^{+}, \mathrm{GAD}^{+} 7^{+}$, or GAD65 $^{+}$ACs. $\boldsymbol{F}-\boldsymbol{F}^{\prime \prime}, \mathbf{G}-\boldsymbol{G}^{\prime \prime}$, $\boldsymbol{H}-\boldsymbol{H}^{\prime \prime}, \mathrm{All}_{\mathrm{TH}}{ }^{+}, \mathrm{AADC}^{+}$, or p57Kip2 ${ }^{+}$neurons coexpress Nr4a2. I-I", Nr4a2 is not expressed in GLYT1 ${ }^{+}$glycinergic ACs. J-J", Nr4a2 is not colocalized with calbindin in ACs or horizontal cells. Arrowheads point to representative colocalized cells, and insets show corresponding outlined regions at a higher magnification. Scale bar: A-J", $47.6 \mu \mathrm{m}$.

To identify the types of cells that express Nr4a2, we performed a series of double-immunofluorescence labeling with a variety of cell type-specific markers and used confocal microscopy to determine colocalized cells. Consistent with it being expressed by ACs, $\mathrm{Nr} 4 \mathrm{a} 2$ is colocalized with syntaxin and Pax6, two pan-AC protein markers, in all of Nr4a2-expressing cells (Fig. $3 A-A^{\prime \prime}, B-B^{\prime \prime}$ ); additionally, most Nr4a2-expressing cells also express other AC markers including calretinin and AP-2 $\alpha$ (supplemental Fig. S1 A$A^{\prime \prime}, B-B^{\prime \prime}$, available at www.jneurosci.org as supplemental material) (Bassett et al., 2007). There appears to be a complete colocalization between Nr4a2 and GABA, GAD67 (glutamic decarboxylase 67) and GAD65 in Nr4a2-expressing cells (Fig. 3C$\left.C^{\prime \prime}, D-D^{\prime \prime}, E-E^{\prime \prime}\right)$, indicating the expression of Nr4a2 in a subset of GABAergic amacrine neurons. In agreement with its expression in dopaminergic neurons elsewhere, $\mathrm{Nr} 4 \mathrm{a} 2$ is found in all dopaminergic ACs that are immunoreactive for TH and AADC (Fig. $\left.3 F-F^{\prime \prime}, G-G^{\prime \prime}\right)$. Additionally, Nr4a2 is seen in all cells immunoreactive for p57Kip2 (Fig. $3 H-H^{\prime \prime}$ ), a cyclin-dependent kinase inhibitor that marks a subpopulation of GABAergic ACs that exclude the dopaminergic neurons (Dyer and Cepko, 2000, 2001).

Bhlhb5 marks another subset of GABAergic ACs (Feng et al., 2006), but its expression and that of $\mathrm{Nr} 4 \mathrm{a} 2$ are mutually exclusive (supplemental Fig. S1C- $C^{\prime \prime}$, available at www.jneurosci.org as supplemental material). There is no expression of Nr4a2 in glycinergic ACs immunoreactive for GLYT1 (glycine transporter 1), nor is it expressed in ACs immunoreactive for calbindin or Isl1, which label retinal cells that include cholinergic amacrine neurons (Fig. 3I-I" $J-J^{\prime \prime}$; supplemental Fig. S1 $J-J^{\prime \prime}$, available at www. jneurosci.org as supplemental material) (Haverkamp and Wassle, 2000; Elshatory et al., 2007). Nr4a2 is not expressed in ganglion cells immunoreactive for Brn3a, Brn3b, or Isl1 (supplemental Fig. $S 1 D-D^{\prime \prime}, E-E^{\prime \prime}, J-J^{\prime \prime}$, available at www.jneurosci.org as supple- 

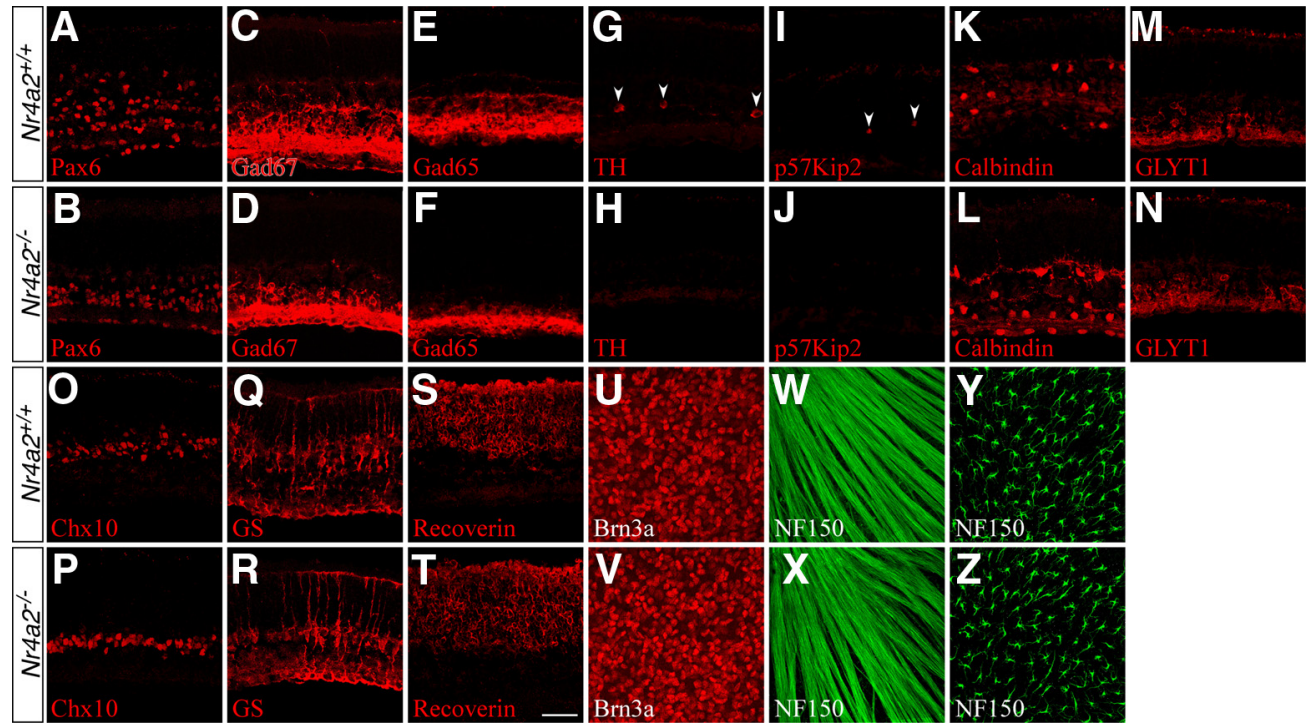

Figure 4. Effect of targeted $\mathrm{Nr} 4 \mathrm{a} 2$ deletion on the formation of different retinal cell types. $A-T$, Sections from PO Nr4a2 $2^{+/+}$and $N r 4 a 2^{-1-}$ retinal explants that were cultured for 2 weeks were immunostained with antibodies against the indicated cell type-specific markers. Loss of Nr4a2 function results in a significant decrease of ACs immunoreactive for Pax6 $(\boldsymbol{A}, \boldsymbol{B})$, Gad67 (C, D), or Gad65 $(\boldsymbol{E}, \boldsymbol{F})$ as well as a complete loss of $\mathrm{TH}^{+}$dopaminergic $\mathrm{ACs}(\boldsymbol{G}, \boldsymbol{H})$ and p57Kip2 ${ }^{+} \mathrm{ACs}(\boldsymbol{I}, \boldsymbol{J})$. In addition, it causes a significant increase of calbindin ${ }^{+} \mathrm{ACs}(\boldsymbol{K}, \boldsymbol{L})$. However, there is no difference between $\mathrm{Nr}_{\mathrm{ra2}}{ }^{+/+}$and $\mathrm{Nr}_{4 a 2^{-/-}}$retinas in the number of glycinergic ACs immunoreactive for GLYT1 $(\boldsymbol{M}, \boldsymbol{N})$, bipolar cells immunoreactive for Chx10 $(\boldsymbol{O}, \boldsymbol{P})$, Müller cells immunoreactive for glutamine synthase $(G S)(\boldsymbol{Q}, \boldsymbol{R})$, and photoreceptor cells immunoreactive for recoverin $(\boldsymbol{S}, \boldsymbol{T}) . \boldsymbol{U}-\boldsymbol{Z}, \mathrm{PONr} 4 a 2^{+/+}$and Nr4a2${ }^{-/-}$whole-mount retinas were immunostained with anti-Brn3a $(\boldsymbol{U}, \boldsymbol{V})$ or anti-NF150 (W-Z) antibodies. The confocal images in $\boldsymbol{W}$ and $\boldsymbol{X}$ were focused on the nerve fiber layer and in $\boldsymbol{Y}$ and $\boldsymbol{Z}$ on the horizontal cell layer. In Nr4a2 ${ }^{-1-}$ retinas, there is no significant change

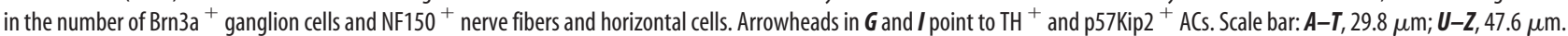

mental material), bipolar cells immunoreactive for PKC, Chx10, or Prox1 (supplemental Fig. $S 1 F-F^{\prime \prime}, G-G^{\prime \prime}, H-H^{\prime \prime}$, available at www.jneurosci.org as supplemental material), horizontal cells immunoreactive for Lim1, calbindin, or Prox1 (Fig. 3J-J"; supplemental Fig. S1 $H-H^{\prime \prime}, I-I^{\prime \prime}$, available at www.jneurosci.org as supplemental material), or Müller cells immunoreactive for glutamine synthase (supplemental Fig. S1 $K-K^{\prime \prime}$, available at www. jneurosci.org as supplemental material).

Quantification of colocalized cells revealed that the proportions of Nr4a2-expressing cells in the syntaxin ${ }^{+}, \mathrm{Pax}^{+}$, $\mathrm{GABA}^{+}, \mathrm{Gad}_{67}{ }^{+}$, and $\mathrm{Gad} 65^{+}$populations are only $13.1 \%$, $10.9 \%, 27.5 \%, 20 \%$, and $21.9 \%$, respectively, whereas $100 \%$ of p57Kip $2{ }^{+}$and $\mathrm{TH}^{+}$cells coexpress $\mathrm{Nr} 4 \mathrm{a} 2$ (supplemental Fig. S2, available at www.jneurosci.org as supplemental material). Thus, $\mathrm{Nr} 4 \mathrm{a} 2$ is expressed only by a subset of GABAergic ACs that include all dopaminergic neurons and the population that express p57Kip2.

\section{Loss of GABAergic amacrine cells in $\mathrm{Nr4a2}$-null retinas}

To understand the role of $\mathrm{Nr} 4 \mathrm{a} 2$ during mouse retinogenesis, we investigated the effect of its inactivation on retinal cell development. Due to perinatal lethality of Nr4a2-null mutant mice (Zetterström et al., 1997; Saucedo-Cardenas et al., 1998), P0 retinal explants were cultured for 2 weeks [14 DIV (days in vitro)] for analysis of various retinal cell types in control and mutant retinas. We found that the number of Pax6-, GABA-, Gad67-, and Gad65-immunoreactive ACs decreased by 27\%, 34\%, 24\%, and $20 \%$, respectively, in mutant retinas compared with the control (Figs. $4 A-F, 5 A$ ), consistent with the expression of $\mathrm{Nr} 4 \mathrm{a} 2$ in GABAergic ACs. In addition, the TH-immunoreactive dopaminergic neurons and p57Kip2-immunoreactive GABAergic ACs all disappeared in the null retina (Figs. $4 G-J, 5 A$ ), in agreement with the observation that $\mathrm{Nr} 4 \mathrm{a} 2$ is localized in all TH- and p57Kip2expressing cells. In contrast, calbindin-immunoreactive ACs increased by $31 \%$ in the $N r 4 a 2$ mutant retina (Figs. $4 K, L, 5 A$ ), suggesting a possible fate change and consistent with the significant increase seen in $p 57 \mathrm{Kip}^{-l-}$ retinas (Dyer and Cepko, 2000). In $N r 4 a 2^{-1-}$ retinas, no change was observed in the number of calretinin-immunoreactive ACs and GLYT1-immunoreactive glycinergic ACs (Figs. $4 M, N, 5 A$ ). Similarly, there was no alteration in the number of horizontal cells immunoreactive for calbindin, bipolar cells immunoreactive for Chx10, Müller cells immunoreactive for glutamine synthase, and photoreceptors immunoreactive for recoverin (Figs. $4 K, L, O-T, 5 A$ ). In $\mathrm{P} 0$ control and $\mathrm{Nr} 4 a 2^{-1-}$ retinas, there were similar numbers of ganglion cells immunoreactive for Brn3a, horizontal cells immunoreactive for NF150 as well as nerve fibers labeled for NF150 (Fig. 4U-Z). Thus, the absence of Nr4a2 leads to selective loss of GABAergic ACs including all dopaminergic neurons and p57Kip ${ }^{+} \mathrm{ACs}$ while increasing the calbindin ${ }^{+}$ACs.

It is possible that all GABAergic ACs might be initially specified in Nr4a2-null mutant retinas but then gradually degenerate later during development. To test this possibility, we cultured P0 retinas for only $4.5 \mathrm{~d}$ (4.5 DIV) before analyses with various AC markers. Similar to retinas at 14 DIV, the number of syntaxin-, Pax6-, Gad67-, and p57Kip2-immunoreactive ACs diminished by $24 \%, 33 \%, 27 \%$, and $92 \%$, respectively, in mutant retinas at 4.5 DIV; whereas calbindin-immunoreactive ACs increased by $66 \%$ (supplemental Fig. S3A-N, available at www.jneurosci.org as supplemental material; Fig. $5 B$ ). There were similar numbers of GLYT1- or calretinin-immunoreactive ACs and calbindinimmunoreactive horizontal cells in wild-type and mutant retinas at 4.5 DIV (supplemental Fig. S3M-R, available at www. jneurosci.org as supplemental material; Fig. $5 B$ ). Therefore, it appears that a subset of GABAergic ACs fail to generate and at least some of them are misspecified into calbindin ${ }^{+} \mathrm{ACs}$ in the absence of $\mathrm{Nr} 4 \mathrm{a} 2$. Given that Bhlhb5 is expressed in and required for specifying a subset of GABAergic ACs (Feng et al., 2006), we examined its expression in the null retina and found no significant change (supplemental Fig. S3S,T, available at 
A
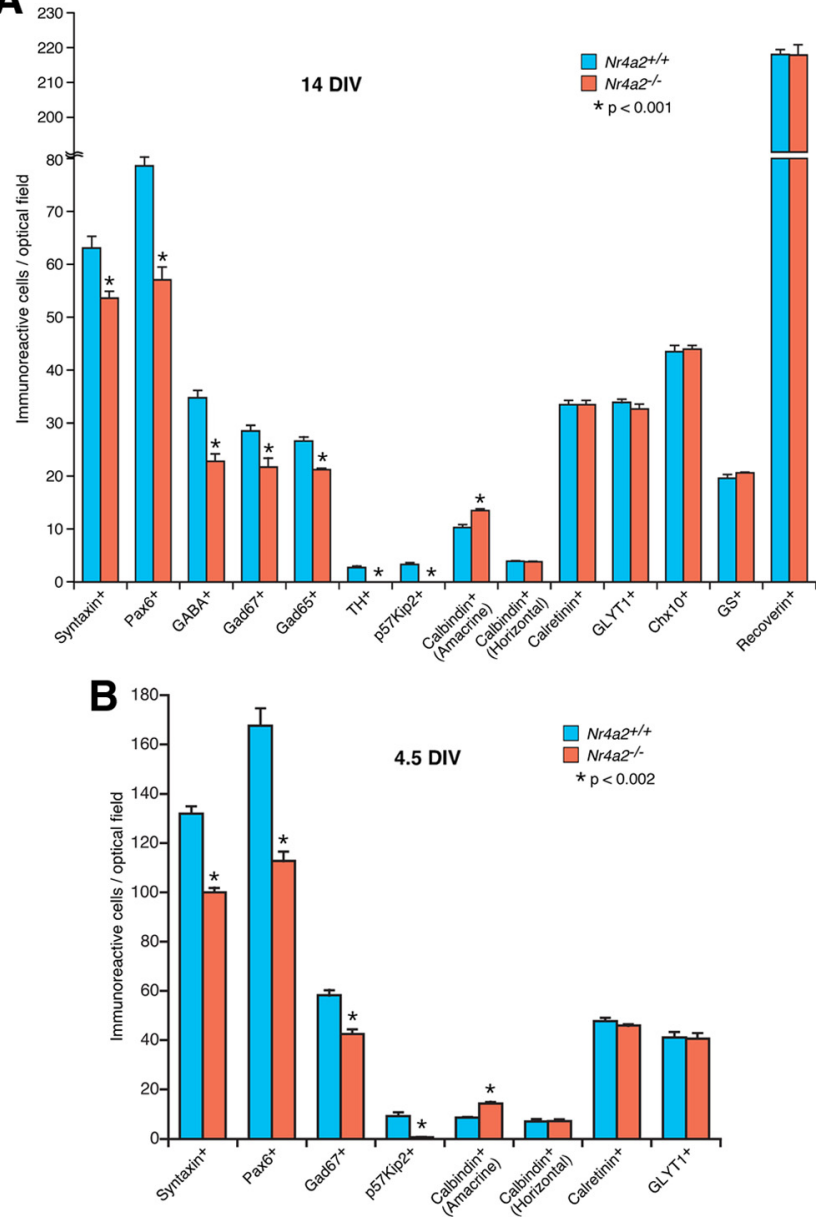

Figure 5. Quantitation of cells that are immunoreactive for various cell type-specific markers in P0 Nr4a2 $2^{+/+}$and $\mathrm{Nr}_{\mathrm{ra2}} 2^{-1-}$ retinal explants cultured for $14(\boldsymbol{A})$ and 4.5 (B) DIV (days in vitro). Each histogram represents the mean \pm SD for four retinas. Note that all marker-positive cells were counted under a fluorescent microscope at a magnification of 1000 except for p57Kip2 ${ }^{+} \mathrm{ACs}$ and calbindin ${ }^{+}$horizontal cells, which were counted at a magnification of 400 , and $\mathrm{TH}^{+} \mathrm{ACs}$, which were counted at a magnification of 100 , due to the paucity of these positive cells.

www.jneurosci.org as supplemental material), consistent with the nonoverlapping expression pattern between $\mathrm{Nr} 4 \mathrm{a} 2$ and Bhlhb5 (supplemental Fig. S1C-C", available at www.jneurosci. org as supplemental material) and suggesting that Nr4a2 controls GABAergic AC development independent of Bhlhb5.

\section{Enhanced cell death in $N r 4 a 2^{-1-}$ retinas}

The improper specification of GABAergic ACs from retinal precursors in $\mathrm{Nr} 4 \mathrm{a} 2^{-1-}$ retinas may result in primary and/or secondary retinal cell degeneration by apoptosis. To test this, we measured apoptotic cell death in wild-type and mutant retinas. As determined by TUNEL, no significant difference was observed in the number of labeled cells in $\mathrm{P} 0$ mutant retinas or in $\mathrm{P} 0$ mutant retinas cultured for $4.5 \mathrm{DIV}$ (Fig. $6 A-D, G$ ). In contrast, P0 null retinas cultured for 14 DIV displayed a $45 \%$ increase of apoptotic cell death (Fig. $6 \mathrm{E}-\mathrm{G}$ ). In $\mathrm{Nr} 4 a 2^{-1-}$ retinas at $14 \mathrm{DIV}$, most cells undergoing apoptosis were seen within the inner edge of the outer nuclear layer (ONL) rather than in the INL (Fig. 6F), suggesting that some inappropriately differentiated cells or photoreceptors instead of ACs undergo enhanced apoptosis. This is consistent with the idea that a subpopulation of GABAergic ACs fail to generate or are improperly specified in the absence of Nr4a2.

\section{Nr4a2 misexpression promotes the GABAergic amacrine cell fate}

Given its requirement in specifying GABAergic ACs, we next tested whether Nr4a2 was sufficient to promote this particular cell fate from retinal precursors by a gain-of-function approach using a replication-incompetent murine retroviral vector that carries a GFP reporter (supplemental Fig. S4A, available at www. jneurosci.org as supplemental material) (Li et al., 2004; Mo et al., 2004). Retinal progenitors were infected at P0 by subretinal injection of Nr4a2-GFP or control-GFP viruses, and we analyzed the laminar position and morphology of $\mathrm{GFP}^{+}$cells in infected retinas at $\mathrm{P} 21$. In control retinas, the great majority of $\mathrm{GFP}^{+}$cells differentiated as photoreceptors randomly distributed within the ONL, with $43.9 \%$ of their cell bodies located in the outer half of the ONL and $41.6 \%$ in the inner half of the ONL (supplemental Fig. $\mathrm{S} 4 B, E$, available at www.jneurosci.org as supplemental material). In retinas infected with $\mathrm{Nr} 4 \mathrm{a} 2-\mathrm{GFP}$ viruses, however, $53.9 \%$ of $\mathrm{GFP}^{+}$cells were seen in the outer half of the ONL and only $14.4 \%$ in the inner half of the ONL (supplemental Fig. $S 4 C, E$, available at www.jneurosci.org as supplemental material). Moreover, most of the GFP ${ }^{+}$cells in the ONL lacked the inner and outer segments characteristic of photoreceptors seen in control retinas (supplemental Fig. $\mathrm{S} 4 B, C$, available at www. jneurosci.org as supplemental material). In the INL, the fraction of $\mathrm{GFP}^{+}$cells increased from $15.8 \%$ in the control to $30.4 \%$ in retinas infected with $\mathrm{Nr} 4 \mathrm{a} 2-\mathrm{GFP}$ viruses (supplemental Fig. $\mathrm{S} 4 B, C, E$, available at www.jneurosci.org as supplemental material). Similarly, there was a significant increase in the number of $\mathrm{GFP}^{+}$cells distributed in the GCL of retinas infected with Nr4a2GFP viruses (supplemental Fig. S4B,C,E, available at www. jneurosci.org as supplemental material). Thus, $\mathrm{Nr} 4 \mathrm{a} 2$ misexpression in progenitors substantially changes the proportions of progeny distributed in different retinal cell layers.

The increased $\mathrm{GFP}^{+}$cells in the INL and GCL of retinas infected with Nr4a2-GFP viruses could represent more amacrine, ganglion, horizontal, bipolar, and/or Müller cells. To distinguish these possibilities, we used a series of cell type-specific markers to analyze the types of cells that were differentiated from the virusinfected progenitors. First, misexpressed Nr4a2 increased 3-4fold the number of $\mathrm{GFP}^{+} \mathrm{ACs}$ that were immunoreactive for Pax6, GABA, or GAD67 (Figs. 7A, $B, D, E, G, H, 8$ ), whereas it reduced calbindin-immunoreactive ACs by $45 \%$ and had no effect on glycinergic $\left(\mathrm{GLYT}^{+}{ }^{+}\right.$) ACs (Figs. $\left.7 J, K, M, N, 8\right)$. This is in agreement with the specific loss of GABAergic ACs and significant increase of calbindin ${ }^{+}$ACs in Nr4a2-null retinas. Second, there was no effect exerted by misexpressed $\mathrm{Nr} 4 \mathrm{a} 2$ on the number of Chx10immunoreactive bipolar cells, calbindin-immunoreactive horizontal cells, Brn3a-immunoreactive ganglion cells, or glutamine synthase-immunoreactive Müller cells (Figs. 7 P, Q,S,T, 8; data not shown). Finally, misexpressed $\mathrm{Nr} 4 \mathrm{a} 2$ reduced the proportion of recoverin $^{+}$photoreceptor cells from $83 \%$ to $18.7 \%$ (Figs. $7 \mathrm{~V}, W, 8)$. In retinas infected with $\mathrm{Nr} 4 \mathrm{a} 2-\mathrm{GFP}$ viruses, most of the $\mathrm{GFP}^{+}$cells $(59.6 \%$ of all) were located within the outer half of the ONL, nonimmunoreactive for the above-tested markers, and were additionally negative for red/green opsin, blue opsin, nestin, NeuN, and Otx2 (Fig. 8; supplemental Fig. S4 B, C, available at www.jneurosci.org as supplemental material; data not shown), suggesting them as some kind of immature cells whose differentiation is prevented by misexpressed $\mathrm{Nr} 4 \mathrm{a} 2$. The formation of these unidentified cells in large quantity as well as more 

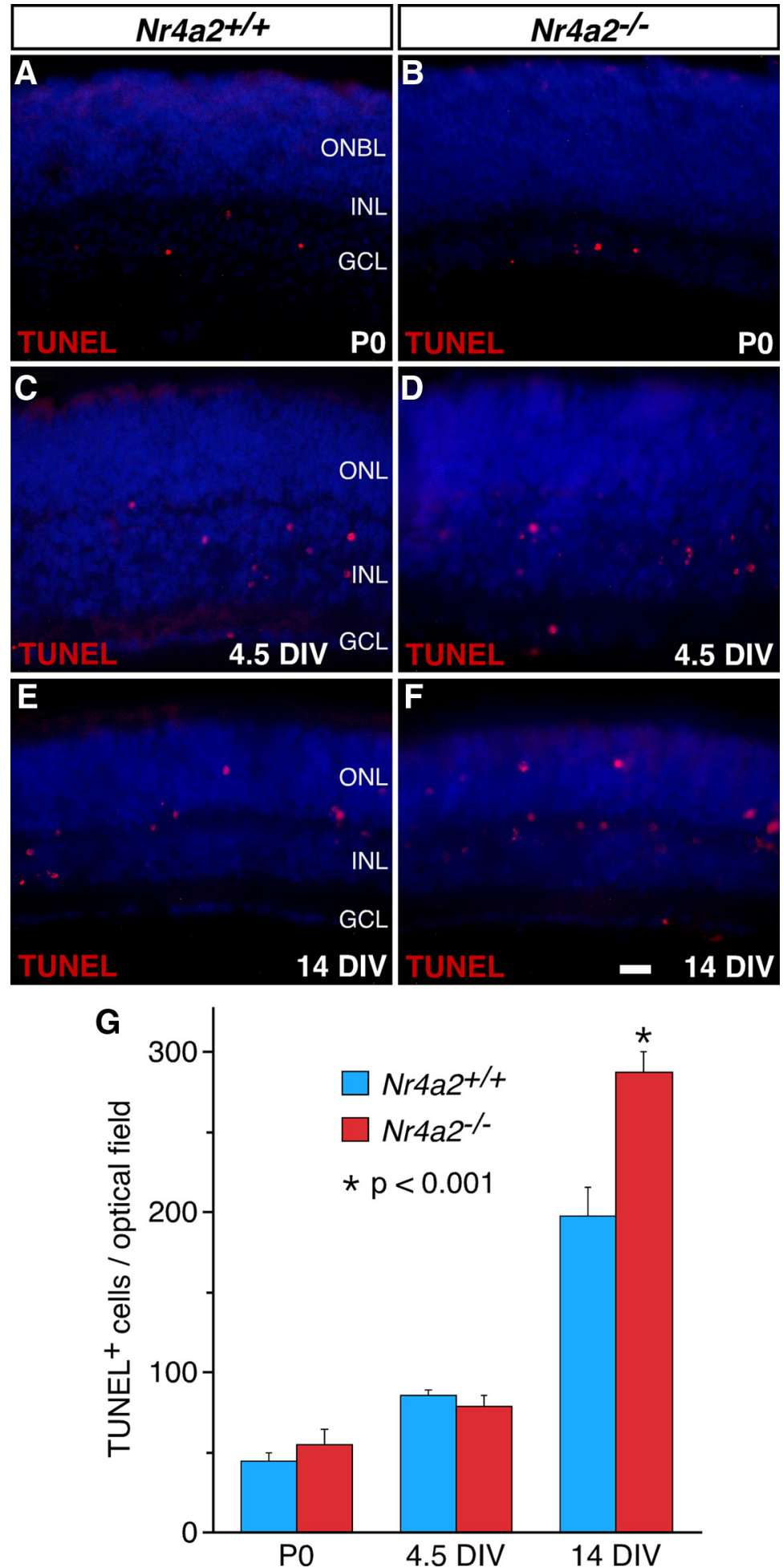

Figure 6. Increased cell death in $\mathrm{Nr}_{4} \mathrm{a} 2^{-/-}$retinas. $A-F$, Cells undergoing apoptosis were TUNEL-labeled in sections from $\mathrm{PO}$ $\mathrm{Nr}_{4 a 2^{+/+}}$and $\mathrm{Nr}_{4} \mathrm{a}^{-/-}$retinas $(\boldsymbol{A}, \boldsymbol{B})$ and from PO retinal explants cultured for $4.5(\boldsymbol{C}, \boldsymbol{D})$ and $14(\boldsymbol{E}, \boldsymbol{F})$ DIV (days in vitro). In null mutant retinas, there is a significant increase of TUNEL-labeled cells at 14 DIV but no change in the number of these cells at $\mathrm{P} 0$ and 4.5 DIV. G, Quantitation of apoptotic cell death in PO $\mathrm{Nr}_{4} \mathrm{a2}^{+/+}$and $\mathrm{Nr}_{4} \mathrm{a2}^{-/-}$retinas and retinal explants. Each histogram represents the mean \pm SD for four retinas. ONBL, Outer neuroblastic layer. Scale bar: $\boldsymbol{A}, \boldsymbol{B}, 25 \mu \mathrm{m} ; \boldsymbol{C}-\boldsymbol{F}, 16.7 \mu \mathrm{m}$.

GABAergic ACs may cause a depletion of virus-transduced retinal progenitors which in turn may result in the observed dramatic reduction of photoreceptor cells.

When $\mathrm{P} 0$ retinas were infected with either control-GFP or Nr4a2-GFP viruses, few, if any, $\mathrm{GFP}^{+}$cells became p57Kip2 ${ }^{+}$
ACs perhaps because postnatal retinal progenitors are incompetent of generating this subpopulation of cells. To test this speculation, we infected retinal explants at E14.5 and harvested them after $12 \mathrm{~d}$ in culture for analysis. We found that in retinas infected with $\mathrm{Nr} 4 \mathrm{a} 2-\mathrm{GFP}$ viruses, there were $\sim 4.5 \%$ of $\mathrm{GFP}^{+}$cells coexpressing $\mathrm{p} 57 \mathrm{Kip} 2$, whereas in control retinas, cells coexpressing GFP and p57Kip2 were negligible (supplemental Fig. S5, available at www.jneurosci.org as supplemental material). Thus, these misexpression data together demonstrate the ability of $\mathrm{Nr} 4 \mathrm{a} 2$ to bias retinal precursors toward the GABAergic AC fate while suppressing the differentiation of calbindin ${ }^{+}$ACs and photoreceptors.

\section{A dominant-negative form of $\mathrm{Nr} 4 \mathrm{a} 2$ suppresses GABAergic amacrine cell differentiation}

To ask whether Nr4a2 acts as a transcriptional activator for the specification of GABAergic ACs, we constructed a dominant-negative viral plasmid, Nr4a2EnR-GFP, by fusing the repressor domain of the Drosophila engrailed protein to a $\mathrm{Nr} 4 \mathrm{a} 2 \mathrm{~N}$-terminal region that contains the DNA-binding domain (supplemental Fig. S4A, available at www.jneurosci.org as supplemental material). Compared with control retinas, we found that the fractions of $\mathrm{GFP}^{+}$cells immunoreactive for Pax6, GABA, or Gad67 were all reduced by $40-50 \%$ in retinas infected with Nr4a2-EnR-GFP viruses (Figs. 7A,C,D, $F, G, I, 8)$, consistent with $\mathrm{Nr} 4 \mathrm{a} 2$ being an activator for GABAergic AC differentiation. Consistent also with the notion that $\mathrm{Nr} 4 \mathrm{a} 2$ acts as a repressor for the differentiation of calbindin ${ }^{+} \mathrm{ACs}$ and photoreceptor cells, misexpressed Nr4a2-EnR diminished the fractions of $\mathrm{GFP}^{+}$cells that became immunoreactive for calbindin or recoverin (Figs. $7 M, O, V, X, 8$ ). Similar to wild-type Nr4a2, misexpressed Nr4a2-EnR resulted in no changes in the number of GLYT1-immunoreactive ACs, Chx10-immunoreactive bipolar cells, calbindin-immunoreactive horizontal cells, Brn3a-immunoreactive ganglion cells, or glutamine synthase-immunoreactive Müller cells (Figs. 7J, $L, P, R, S, U, 8$; data not shown). Thus, Nr4a2 appears to act as a transcriptional activator to promote GABAergic neuron specification but as a repressor to suppress the differentiation of calbindin ${ }^{+}$ACs and photoreceptor cells.

\section{Discussion}

Among the seven classes of retinal cell types, ACs stand out in that they consist of numerous subtypes with extremely diverse mor- 

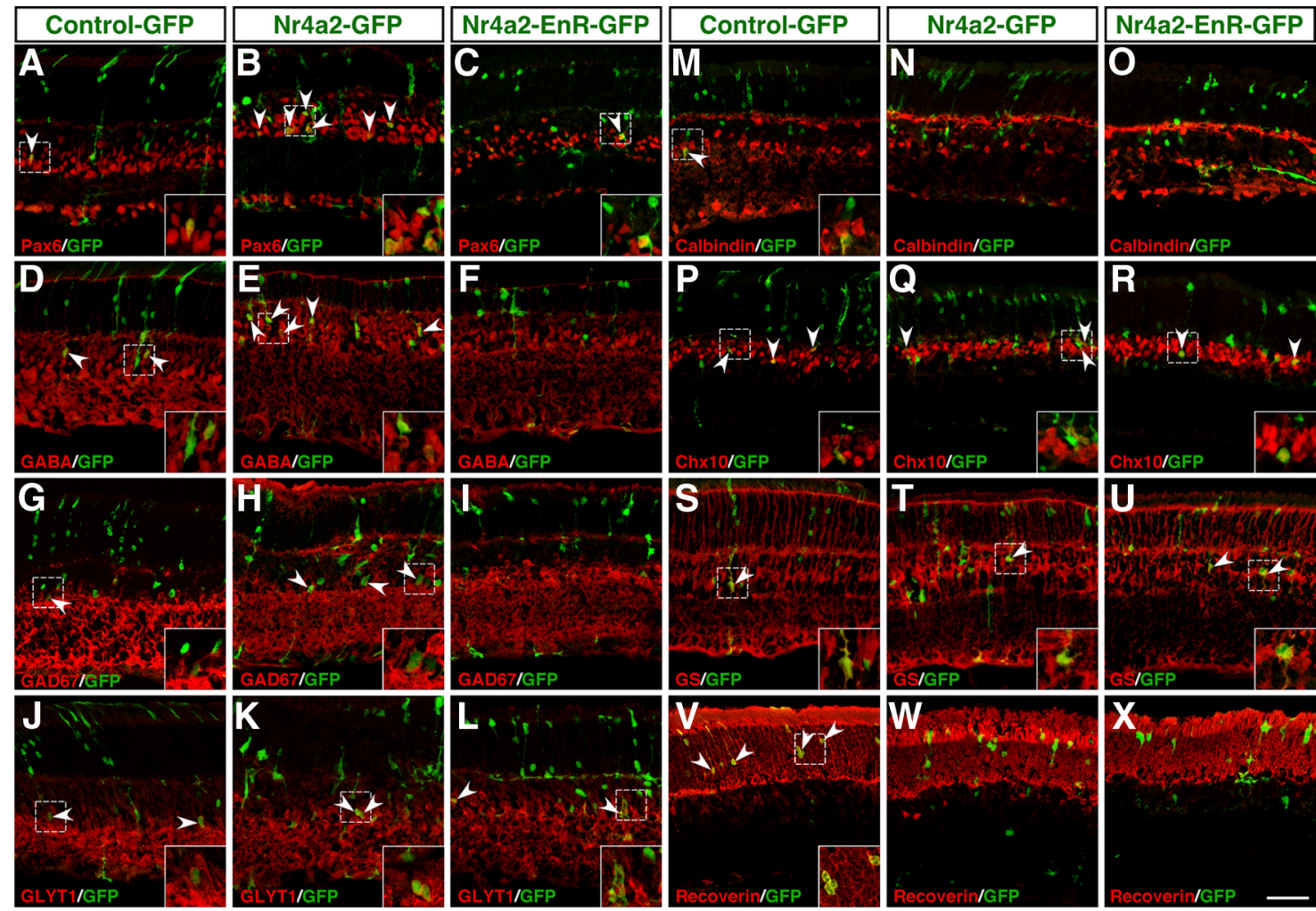

Figure 7. Effect of misexpressed Nr4a2 and its dominant-negative form on the formation of different retinal cell types. $A-X$, Sections from retinas infected with control-GFP, Nr4a2-GFP, or $\mathrm{Nr}$ 4a2-EnR-GFP viruses were double immunostained with an anti-GFP antibody and antibodies against Pax6, GABA, GAD67, GLYT1, calbindin, Chx10, glutamine synthase (GS), or recoverin. Forced expression of wild-type $\mathrm{Nr4a2}$ results in an increase in the number of GABAergic ACs immunoreactive for Pax6, GABA, or GAD67, whereas the dominant-negative form has the opposite effect ( $\boldsymbol{A}-\boldsymbol{I}$ ); however, both the wild-type and dominant-negative forms of Nr4a2 suppress the formation of calbindin ${ }^{+} \mathrm{ACS}(\boldsymbol{M}-\mathbf{0})$ and photoreceptor cells immunoreactive for recoverin $(\boldsymbol{V}-\boldsymbol{X})$. They have no effect on glycinergic ${ }^{+}$ACs immunoreactive for GLYT1 $(\boldsymbol{J}-\boldsymbol{L})$, bipolar cells immunoreactive for $C h x 10(\boldsymbol{P}-\boldsymbol{R})$, and Müller cells immunoreactive for GS $(\boldsymbol{S}-\boldsymbol{U})$. Arrowheads point to representative colocalized cells, and insets show corresponding outlined regions at a higher magnification. Scale bar: $A-X, 39.7 \mu \mathrm{m}$.

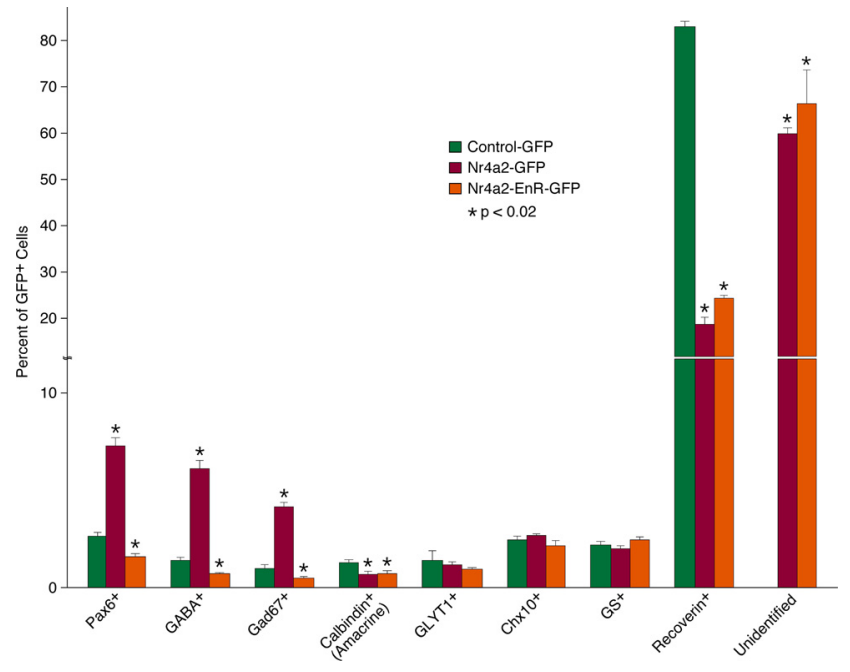

Figure 8. Quantitation of virus-transduced retinal cells that become immunoreactive for a series of cell type-specific markers. Each histogram represents the mean \pm SD for three retinas. The number of GFP ${ }^{+}$cells scored in each retina ranges from 432 to 1333 . The unidentified cells are those that are located at the outer edge of the outer nuclear layer but negative for recoverin.

phologies and physiological functions (MacNeil and Masland, 1998; MacNeil et al., 1999; Masland, 2001a,b). At present, little is known about the intrinsic mechanism that underlies the specification of these distinct AC subtypes. Here, we demonstrate a role for the orphan nuclear receptor $\mathrm{Nr} 4 \mathrm{a} 2$ in the specification of a subset of GABAergic ACs. We find that Nr4a2 colocalizes with a number of GABAergic markers in a subset of ACs that are much more numerous than the dopaminergic AC subset. In $\mathrm{Nr} 4 a 2^{-1-}$ retinas, there is a significant loss of GABAergic ACs that include all dopaminergic ACs and p57Kip2 ${ }^{+}$ACs as well as a simultaneous increase of calbindin ${ }^{+}$ACs. Gain-of-function studies show that misexpressed $\mathrm{Nr} 4 \mathrm{a} 2$ can specifically promote the differentiation of GABAergic ACs while inhibiting that of calbindin ${ }^{+} \mathrm{ACs}$, whereas its dominant-negative form has the ability to suppress the GABAergic AC fate. Our data together thus implicate a role for Nr4a2 in the specification of a subset of GABAergic ACs that include all dopaminergic neurons during mammalian retinogenesis, and further suggest distinct molecular pathways by which other retinogenic factors may promote and suppress GABAergic ACs to ensure proper specification of retinal cell types and subtypes. Compared with previous studies focused on the role of Nr4a2 only in dopaminergic neuron development, our results reveal a function for $\mathrm{Nr} 4 \mathrm{a} 2$ that is much broader than just specifying dopaminergic ACs.

\section{$\mathrm{Nr} 4 \mathrm{a} 2$ specifies a subset of GABAergic amacrine cells during retinogenesis}

Due to the loss of dopaminergic neurons in the ventral tegmental area and substantia nigra in Nr4a2-null mutant mice and its relevance to Parkinson's disease (Zetterström et al., 1997; SaucedoCardenas et al., 1998; Le et al., 2003), numerous previous reports have focused only on the function of $\mathrm{Nr} 4 \mathrm{a} 2$ in dopaminergic neuron development. In this work, we have provided several lines of evidence to demonstrate that at least during retinogenesis $\mathrm{Nr} 4 \mathrm{a} 2$ plays a much broader role in the specification of neuro- 

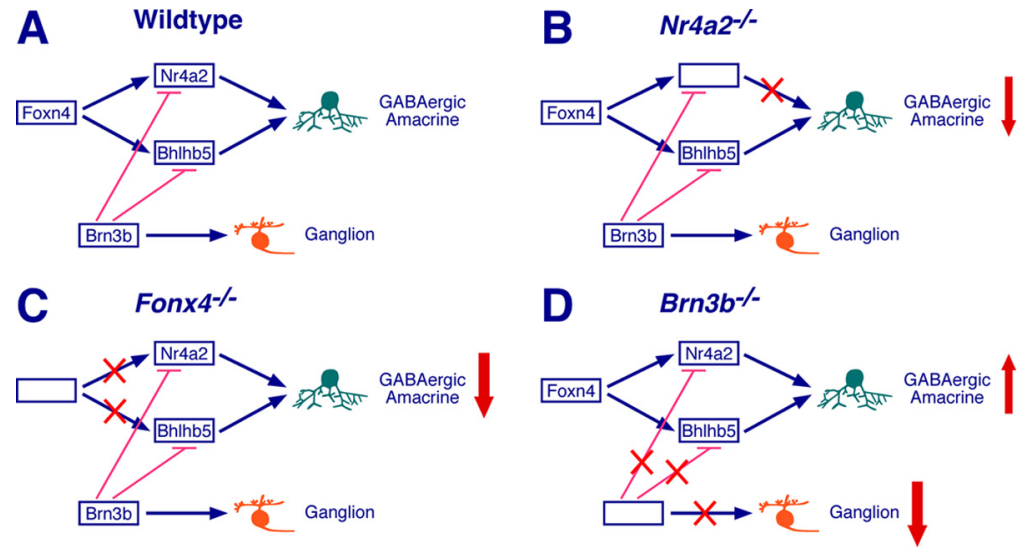

Figure 9. Schematics illustrating the genetic relationship between $\mathrm{Nr} 4 \mathrm{a} 2$ and other retinogenic factors involved in GABAergic AC specification. A, Foxn 4 is required for directly and/or indirectly activating the expression of Nr4a2 and Bhlhb5, which act in parallel to specify GABAergic ACs. While promoting ganglion cell differentiation, Brn3b inhibits GABAergic AC development by repressing the expression of $N r 4 a 2$ and Bhlhb5. B, Nr4a2 inactivation blocks the Nr4a2-dependent pathway to GABAergic AC specification, leading to reduced GABAergic ACs. C, Foxn4 inactivation blocks both the Nr4a2- and Bhlhb5-dependent pathways to GABAergic AC specification, resulting in dramatically reduced GABAergic ACs. D, Brn3b inactivation blocks the Brn3b-dependent pathway to ganglion cell specification as well as causes derepression of $N r 4 a 2$ and $B h / h b 5$ expression, which in turn leads to more GABAergic ACs.

transmitter phenotypes: (1) the onset of Nr4a2 expression (at $\sim$ E16.5) greatly precedes the appearance of TH-expressing dopaminergic ACs (at $\sim$ P12) during retinal development; (2) Nr4a2-expressing cells dramatically outnumber those that express TH and AADC in the mature retina; (3) besides colocalization with $\mathrm{TH}$ and AADC, Nr42a colocalizes with GABAergic markers GABA, GAD65, GAD67, and p57Kip2 in many more ACs; (4) apart from a complete loss of dopaminergic ACs, there is a significant loss of GABAergic ACs and in particular, near complete absence of p57Kip2 ACs in $N r 4 a 2^{-1-}$ retinas; and (5) misexpressed $\mathrm{Nr} 4 \mathrm{a} 2$ is capable of specifically promoting GABAergic AC differentiation, whereas its dominant-negative form has the opposite effect. All these data together suggest that $\mathrm{Nr} 4 \mathrm{a} 2$ may act to specify a subset of GABAergic ACs that include all dopaminergic neurons during mammalian retinogenesis. In fact, $\mathrm{TH}$-immunoreactive cells constitute also only a minor fraction of Nr4a2-expressing ACs in the zebrafish retina (Filippi et al., 2007); hence fish Nr4a2 homologs may be similarly involved in GABAergic AC development.

$\mathrm{Nr} 4 \mathrm{a} 2$ appears to confer the GABAergic identify to a subset of postmitotic AC precursor cells but not likely to be required for the maturation and maintenance of differentiated GABAergic ACs. This is because (1) Nr4a2 expression is found exclusively in postmitotic cells; and (2) in P0 Nr4a2 ${ }^{-1-}$ retinas cultured for only 4.5 DIV when GABAergic ACs are freshly produced, a subpopulation of GABAergic ACs are already missing, indicating that most likely they are not even specified in the first place in the absence of Nr4a2. Thus, all GABAergic AC precursors may be initially generated in the developing mutant retina but some of them may be unable to differentiate and some of them may even change their fates to improperly differentiate as other AC subtypes. Indeed, a fate switch in precursor cells seems likely as we observed a significant increase of calbindin-immunoreactive ACs in the mutant retina. The increased calbindin ${ }^{+}$cells may result from the near complete downregulation of p57Kip2 expression in the null retina as targeted inactivation of $p 57 \mathrm{Kip} 2$ has been shown to cause a similar elevation of calbindin ${ }^{+} \mathrm{ACs}$ (Dyer and Cepko, 2000). Alternatively, p57Kip $2^{+}$and/or $\mathrm{TH}^{+}$ACs may non-cell-autonomously regulate the cell number of calbindin ${ }^{+}$
AC population, and vice versa, to ensure appropriate cell number ratios. The loss of p57 Kip2 ${ }^{+}$and $\mathrm{TH}^{+}$cells in the mutant would then break the cell number control mechanism, leading to an increase of calbindin ${ }^{+}$cells. In Nr4a2 mutant retinas, the AC precursors that fail to differentiate and/or misspecified calbindin ${ }^{+}$ACs may degenerate later during development. Consistent with this notion, in cultured mutant retinal explants, we observed increased apoptosis at 14 DIV and the proportion of calbindin ${ }^{+}$ACs was reduced by half at 14 DIV compared with that at 4.5 DIV (Figs. 5, 6). In the midbrain, $\mathrm{Nr} 4 \mathrm{a} 2$ is found also to be required for specifying dopaminergic neurons from postmitotic precursors. In the mutant brain, dopaminergic neuron precursors are initially generated but fail to differentiate into mature neurons, and they eventually degenerate by apoptosis (SaucedoCardenas et al., 1998; Wallén et al., 1999).

Our data in this report demonstrate that development of dopaminergic neurons in the midbrain and those of retina share some common molecular events. This may provide an explanation why some patients with Parkinson's disease display visual abnormalities, including delayed visual evoked potential and loss of visual contrast sensitivity (Bodis-Wollner and Yahr, 1978; Regan and Maxner, 1987; Raskin et al., 1990; Tagliati et al., 1996). For instance, in patients with familial Parkinson's disease caused by mutations in the NR4A2 locus (Le et al., 2003), abnormal vision may result from the loss of all dopaminergic ACs as well as many other GABAergic ACs.

\section{Distinct molecular pathways leading to the specification of GABAergic amacrine cells}

All amacrine cells are determined and differentiated from multipotent retinal progenitors by the concerted action of a series of intrinsic transcriptional regulators. Foxn 4 confers retinal progenitors with AC-producing competence by activating the expression of Math3, Neurod1, and Ptfla, which are subsequently required for the specification of ACs and their differentiation (Inoue et al., 2002; Li et al., 2004; Fujitani et al., 2006). Once the AC precursors are generated, other more select transcription factors such as Nr4a2, Bhlhb5, Barhl2, and Isl1 may then come into play to further specify them into numerous subtypes (Mo et al., 2004; Feng et al., 2006; Elshatory et al., 2007). The molecular bases underlying subtype specification of neurotransmitter phenotypes is poorly understood at present but our work and other studies implicate distinct molecular pathways. For instance, Pax6 and Barhl2 may be involved in the specification and/or differentiation of glycinergic ACs, whereas Isl1 may be involved in specifying cholinergic ACs (Marquardt et al., 2001; Mo et al., 2004; Elshatory et al., 2007).

Given the previous demonstration of Bhlhb5 in specifying GABAergic ACs (Feng et al., 2006), our current work suggests that $\mathrm{Nr} 4 \mathrm{a} 2$ and Bhlhb5 may independently and parallelly specify two nonoverlapping subsets of GABAergic ACs during retinogenesis. First, Nr4a2 and Bhlhb5 were found not to be colocalized in the same cells (supplemental Fig. S1, available at www. jneurosci.org as supplemental material), implying that they are expressed in two mutually exclusive subpopulations of GABAer- 
gic ACs. Second, there was no change in the number of Bhlhb5immunoreactive cells in Nr4a2-null retinas (supplemental Fig. S3, available at www.jneurosci.org as supplemental material), indicating that the subset of GABAergic ACs that express Bhlhb5 remains intact in the mutant despite significant loss of other GABAergic ACs. Therefore, there exist at least two molecular pathways independently controlled by Nr4a2 and Bhlhb5 that lead to the differentiation of GABAergic ACs during mouse retinal development (Fig. 9A). The functional nonredundancy between Nr4a2 and Bhlhb5 ensures that inactivating either gene would result in the loss of a subset of GABAergic ACs, which is exactly what occurs in either mutant (Fig. 9B) (Feng et al., 2006). Apart from the pathways regulated by $\mathrm{Nr} 4 \mathrm{a} 2$ and Bhlhb5, there might be other ones leading to the GABAergic phenotype. In the Xenopus retina, Ptfla has been shown recently to specifically determine the GABAergic AC fate (Dullin et al., 2007). However, this does not hold true in the mouse retina, where Ptfla is essential for differentiation of both GABAergic and glycinergic ACs (Fujitani et al., 2006; Nakhai et al., 2007).

We have shown previously that targeted disruption of Foxn4 and $B r n 3 b$ in mice causes a dramatic loss and increase of GABAergic ACs, respectively (Li et al., 2004; Qiu et al., 2008). This and other studies delineating the molecular events leading to GABAergic ACs enable us to better understand these mutant phenotypes. In addition to activating the expression of Math3, Neurod1, and Ptf1a (Inoue et al., 2002; Li et al., 2004; Fujitani et al., 2006; Nakhai et al., 2007), all of which are pan-AC specifier genes, Foxn 4 appears to directly and/or indirectly activate the expression of $\mathrm{Nr} 4 \mathrm{a} 2$ and Bhlhb5 as well for GABAergic AC specification (Figs. 1, 9A). Loss of Foxn4 function would disable both differentiation pathways controlled by Nr4a2 and Bhlhb5, thereby resulting in a drastic loss of GABAergic ACs (Fig. 9C). On the contrary, Brn3b normally represses the expression of $\mathrm{Nr} 4 \mathrm{a} 2$ and Bhlhb5 besides specifying ganglion cells and promoting their differentiation (Figs. 1, 9A). The absence of Brn3b would cause ganglion cell loss and derepression of Nr4a2 and Bhlhb5, which in turn would specify more GABAergic ACs (Fig. 9D). Furthermore, the upregulation of $\mathrm{Nr} 4 a 2$ and Bhlhb5 rather than Barhl2, a glycinergic AC specifier gene (Mo et al., 2004), can explain why only GABAergic ACs increase but glycinergic ACs do not change in $B r n 3 b$-null retinas (Qiu et al., 2008). Thus, Nr4a2 appears to network with a number of other retinogenic factors to ensure proper specification and differentiation of retinal cell types and subtypes.

\section{References}

Bassett EA, Pontoriero GF, Feng W, Marquardt T, Fini ME, Williams T, West-Mays JA (2007) Conditional deletion of activating protein $2 \alpha$ $(\mathrm{AP}-2 \alpha)$ in the developing retina demonstrates non-cell-autonomous roles for AP-2 $\alpha$ in optic cup development. Mol Cell Biol 27:7497-7510.

Bodis-Wollner I, Yahr MD (1978) Measurements of visual evoked potentials in Parkinson's disease. Brain 101:661-671.

Cepko CL (1999) The roles of intrinsic and extrinsic cues and bHLH genes in the determination of retinal cell fates. Curr Opin Neurobiol 9:37-46.

Dizhoor AM, Ray S, Kumar S, Niemi G, Spencer M, Brolley D, Walsh KA, Philipov PP, Hurley JB, Stryer L (1991) Recoverin: a calcium sensitive activator of retinal rod guanylate cyclase. Science 251:915-918.

Dullin JP, Locker M, Robach M, Henningfeld KA, Parain K, Afelik S, Pieler T, Perron M (2007) Ptfla triggers GABAergic neuronal cell fates in the retina. BMC Dev Biol 7:110.

Dyer MA, Cepko CL (2000) p57(Kip2) regulates progenitor cell proliferation and amacrine interneuron development in the mouse retina. Development 127:3593-3605.

Dyer MA, Cepko CL (2001) The p57Kip2 cyclin kinase inhibitor is expressed by a restricted set of amacrine cells in the rodent retina. J Comp Neurol 429:601-614.
Elshatory Y, Everhart D, Deng M, Xie X, Barlow RB, Gan L (2007) Islet-1 controls the differentiation of retinal bipolar and cholinergic amacrine cells. J Neurosci 27:12707-12720.

Famiglietti EV Jr, Kolb H (1975) A bistratified amacrine cell and synaptic circuitry in the inner plexiform layer of the retina. Brain Res 84:293-300.

Feng L, Xie X, Joshi PS, Yang Z, Shibasaki K, Chow RL, Gan L (2006) Requirement for Bhlhb5 in the specification of amacrine and cone bipolar subtypes in mouse retina. Development 133:4815-4825.

Filippi A, Dürr K, Ryu S, Willaredt M, Holzschuh J, Driever W (2007) Expression and function of $n r 4 a 2, \operatorname{lm} x 1 b$, and pitx3 in zebrafish dopaminergic and noradrenergic neuronal development. BMC Dev Biol 7:135.

Fujitani Y, Fujitani S, Luo H, Qiu F, Burlison J, Long Q, Kawaguchi Y, Edlund H, MacDonald RJ, Furukawa T, Fujikado T, Magnuson MA, Xiang M, Wright CV (2006) Ptfla determines horizontal and amacrine cell fates during mouse retinal development. Development 133:4439-4450.

Gan L, Xiang M, Zhou L, Wagner DS, Klein WH, Nathans J (1996) POU domain factor Brn-3b is required for the development of a large set of retinal ganglion cells. Proc Natl Acad Sci U S A 93:3920-3925.

Gustincich S, Feigenspan A, Wu DK, Koopman LJ, Raviola E (1997) Control of dopamine release in the retina: a transgenic approach to neural networks. Neuron 18:723-736.

Harris WA (1997) Cellular diversification in the vertebrate retina. Curr Opin Genet Dev 7:651-658.

Haverkamp S, Wässle H (2000) Immunocytochemical analysis of the mouse retina. J Comp Neurol 424:1-23.

Inoue T, Hojo M, Bessho Y, Tano Y, Lee JE, Kageyama R (2002) Math3 and NeuroD regulate amacrine cell fate specification in the retina. Development 129:831-842.

Jensen RJ (1992) Effects of the dopamine antagonist (+)-SCH 23390 on intracellularly recorded responses of ganglion cells in the rabbit retina. Vis Neurosci 8:463-467.

Jensen RJ, Daw NW (1984) Effects of dopamine antagonists on receptive fields of brisk cells and directionally selective cells in the rabbit retina. J Neurosci 4:2972-2985.

Kolb H, Famiglietti EV (1974) Rod and cone pathways in the inner plexiform layer of cat retina. Science 186:47-49.

Le WD, Xu P, Jankovic J, Jiang H, Appel SH, Smith RG, Vassilatis DK (2003) Mutations in NR4A2 associated with familial Parkinson disease. Nat Genet 33:85-89.

Li S, Mo Z, Yang X, Price SM, Shen MM, Xiang M (2004) Foxn4 controls the genesis of amacrine and horizontal cells by retinal progenitors. Neuron 43:795-807.

Liu W, Mo Z, Xiang M (2001) The Ath5 proneural genes function upstream of Brn3 POU domain transcription factor genes to promote retinal ganglion cell development. Proc Natl Acad Sci U S A 98:1649-1654.

Livesey FJ, Cepko CL (2001) Vertebrate neural cell-fate determination: lessons from the retina. Nat Rev Neurosci 2:109-118.

MacNeil MA, Masland RH (1998) Extreme diversity among amacrine cells: implications for function. Neuron 20:971-982.

MacNeil MA, Heussy JK, Dacheux RF, Raviola E, Masland RH (1999) The shapes and numbers of amacrine cells: matching of photofilled with Golgi-stained cells in the rabbit retina and comparison with other mammalian species. J Comp Neurol 413:305-326.

Marquardt T, Ashery-Padan R, Andrejewski N, Scardigli R, Guillemot F, Gruss P (2001) Pax6 is required for the multipotent state of retinal progenitor cells. Cell 105:43-55.

Martinat C, Bacci JJ, Leete T, Kim J, Vanti WB, Newman AH, Cha JH, Gether U, Wang H, Abeliovich A (2006) Cooperative transcription activation by Nurr 1 and Pitx3 induces embryonic stem cell maturation to the midbrain dopamine neuron phenotype. Proc Natl Acad Sci USA 103:2874-2879.

Masland RH (2001a) Neuronal diversity in the retina. Curr Opin Neurobiol 11:431-436.

Masland RH (2001b) The fundamental plan of the retina. Nat Neurosci 4:877-886.

Mo Z, Li S, Yang X, Xiang M (2004) Role of the Barhl2 homeobox gene in the specification of glycinergic amacrine cells. Development 131:1607-1618.

Morrow EM, Furukawa T, Lee JE, Cepko CL (1999) NeuroD regulates multiple functions in the developing neural retina in rodent. Development 126:23-36.

Nakhai H, Sel S, Favor J, Mendoza-Torres L, Paulsen F, Duncker GI, Schmid 
RM (2007) Ptfla is essential for the differentiation of GABAergic and glycinergic amacrine cells and horizontal cells in the mouse retina. Development 134:1151-1160.

Piccolino M, Witkovsky P, Trimarchi C (1987) Dopaminergic mechanisms underlying the reduction of electrical coupling between horizontal cells of the turtle retina induced by $\mathrm{d}$-amphetamine, bicuculline, and veratridine. J Neurosci 7:2273-2284.

Qiu F, Jiang H, Xiang M (2008) A comprehensive negative regulatory program controlled by Brn3b to ensure ganglion cell specification from multipotential retinal precursors. J Neurosci 28:3392-3403.

Raskin SA, Borod JC, Wasserstein J, Bodis-Wollner I, Coscia L, Yahr MD (1990) Visuospatial orientation in Parkinson's disease. Int J Neurosci 51:9-18.

Regan D, Maxner C (1987) Orientation-selective visual loss in patients with Parkinson's disease. Brain 110:415-432.

Saucedo-Cardenas O, Quintana-Hau JD, Le WD, Smidt MP, Cox JJ, De Mayo F, Burbach JP, Conneely OM (1998) Nurr1 is essential for the induction of the dopaminergic phenotype and the survival of ventral mesencephalic late dopaminergic precursor neurons. Proc Natl Acad Sci U S A 95:4013-4018.

Strettoi E, Raviola E, Dacheux RF (1992) Synaptic connections of the narrow-field, bistratified rod amacrine cell (AII) in the rabbit retina. J Comp Neurol 325:152-168.

Tagliati M, Bodis-Wollner I, Yahr MD (1996) The pattern electroretinogram in Parkinson's disease reveals lack of retinal spatial tuning. Electroencephalogr Clin Neurophysiol 100:1-11.

Vaney DI (1985) The morphology and topographic distribution of AII amacrine cells in the cat retina. Proc R Soc Lond B Biol Sci 224:475-488.

Vaney DI (1990) The mosaic of amacrine cells in the mammalian retina. Prog Retin Res 9:49-100.

Wallén A, Zetterström RH, Solomin L, Arvidsson M, Olson L, Perlmann T (1999) Fate of mesencephalic AHD2-expressing dopamine progenitor cells in NURR1 mutant mice. Exp Cell Res 253:737-746.

Wang Z, Benoit G, Liu J, Prasad S, Aarnisalo P, Liu X, Xu H, Walker NP, Perlmann T (2003) Structure and function of Nurr1 identifies a class of ligand-independent nuclear receptors. Nature 423:555-560.

Xiang M (1998) Requirement for Brn-3b in early differentiation of postmitotic retinal ganglion cell precursors. Dev Biol 197:155-169.

Zetterström RH, Solomin L, Jansson L, Hoffer BJ, Olson L, Perlmann T (1997) Dopamine neuron agenesis in Nurr1-deficient mice. Science 276: $248-250$ 